\title{
C1q Deficiency
}

National Cancer Institute

\section{Source}

National Cancer Institute. C1q Deficiency. NCI Thesaurus. Code C119990.

Lack of production of functional C1q proteins, due to a genetic defect. Virtually $100 \%$ of patients with a C1q deficiency will develop a severe systemic lupus erythematosus at an early age. Patients also present with frequent sinopulmonary infections often with Streptococcus pneumoniae. 